\title{
Computed tomography assessment of PEEP-induced alveolar recruitment in patients with severe COVID-19 pneumonia
}

Lorenzo Ball ${ }^{1,2^{*}}$, Chiara Robba², Lorenzo Maiello', Jacob Herrmann³, Sarah E. Gerard ${ }^{4}$, Yi Xin $^{5}$, Denise Battaglini ${ }^{2}$, lole Brunetti ${ }^{2}$, Giuseppe Minetti ${ }^{6}$, Sara Seitun ${ }^{6}$, Antonio Vena ${ }^{7}$, Daniele Roberto Giacobbe ${ }^{7}$, Matteo Bassetti ${ }^{7,8}$, Patricia R. M. Rocco ${ }^{9}$, Maurizio Cereda ${ }^{10}$, Lucio Castellann ${ }^{6}$, Nicolò Patroniti ${ }^{1,2}$ and Paolo Pelosi ${ }^{1,2}$ on behalf of GECOVID (GEnoa COVID-19) group

\begin{abstract}
Background: There is a paucity of data concerning the optimal ventilator management in patients with COVID19 pneumonia; particularly, the optimal levels of positive-end expiratory pressure (PEEP) are unknown. We aimed to investigate the effects of two levels of PEEP on alveolar recruitment in critically ill patients with severe COVID-19 pneumonia.

Methods: A single-center cohort study was conducted in a 39-bed intensive care unit at a university-affiliated hospital in Genoa, Italy. Chest computed tomography (CT) was performed to quantify aeration at 8 and $16 \mathrm{cmH}_{2} \mathrm{O}$ PEEP. The primary endpoint was the amount of alveolar recruitment, defined as the change in the non-aerated compartment at the two PEEP levels on CT scan.
\end{abstract}

Results: Forty-two patients were included in this analysis. Alveolar recruitment was median [interquartile range] 2.7 [0.7-4.5] \% of lung weight and was not associated with excess lung weight, $\mathrm{PaO}_{2} / \mathrm{FiO}_{2}$ ratio, respiratory system compliance, inflammatory and thrombophilia markers. Patients in the upper quartile of recruitment (recruiters), compared to non-recruiters, had comparable clinical characteristics, lung weight and gas volume. Alveolar recruitment was not different in patients with lower versus higher respiratory system compliance. In a subgroup of 20 patients with available gas exchange data, increasing PEEP decreased respiratory system compliance (median difference, MD $-9 \mathrm{ml} /$ $\mathrm{cmH}_{2} \mathrm{O}, 95 \% \mathrm{Cl}$ from -12 to $\left.-6 \mathrm{ml} / \mathrm{cmH}_{2} \mathrm{O}, p<0.001\right)$ and the ventilatory ratio $(\mathrm{MD}-0.1,95 \% \mathrm{Cl}$ from -0.3 to -0.1 , $p=0.003$ ), increased $\mathrm{PaO}_{2}$ with $\mathrm{FiO}_{2}=0.5$ (MD $24 \mathrm{mmHg}, 95 \% \mathrm{Cl}$ from 12 to $51 \mathrm{mmHg}, p<0.001$ ), but did not change $\mathrm{PaO}_{2}$ with $\mathrm{FiO}_{2}=1.0$ (MD $7 \mathrm{mmHg}, 95 \% \mathrm{Cl}$ from -12 to $49 \mathrm{mmHg}, p=0.313$ ). Moreover, alveolar recruitment was not correlated with improvement of oxygenation or venous admixture.

Conclusions: In patients with severe COVID-19 pneumonia, higher PEEP resulted in limited alveolar recruitment. These findings suggest limiting PEEP strictly to the values necessary to maintain oxygenation, thus avoiding the use of higher PEEP levels.

Keywords: COVID-19, ARDS, Respiratory system mechanics, Mechanical ventilation, CT scan

*Correspondence: lorenzo.ball@unige.it

${ }^{1}$ Department of Surgical Sciences and Integrated Diagnostics (DISC),

University of Genoa, Viale Benedetto XV 16, Genoa, Italy

Full list of author information is available at the end of the article original author(s) and the source, provide a link to the Creative Commons licence, and indicate if changes were made. The images or other third party material in this article are included in the article's Creative Commons licence, unless indicated otherwise in a credit line to the material. If material is not included in the article's Creative Commons licence and your intended use is not permitted by statutory regulation or exceeds the permitted use, you will need to obtain permission directly from the copyright holder. To view a copy of this licence, visit http://creativecommons.org/licenses/by/4.0/. The Creative Commons Public Domain Dedication waiver (http://creativeco mmons.org/publicdomain/zero/1.0/) applies to the data made available in this article, unless otherwise stated in a credit line to the data. 


\section{Introduction}

Over the last months, the global pandemic from coronavirus disease 2019 (COVID-19) has posed important challenges to intensive care unit (ICU) physicians $[1,2]$. A significant proportion of COVID-19 patients develop severe hypoxemic respiratory failure requiring invasive mechanical ventilation $[2,3]$. Although COVID-19 meets the clinical criteria for acute respiratory distress syndrome (ARDS) [4], peculiar pathophysiological features [5] and phenotypes have been identified in this disease [6]. In COVID-19 patients, chest computed tomography (CT) findings typically include ground glass opacities overlapping with areas of lung consolidation, not always reflecting the severity of gas-exchange impairment [7]. In this context, severe hypoxemia might be related not only to loss of aeration, but also to highly perfused groundglass areas [8, 9]. In COVID-19 patients with high respiratory system compliance and low ventilation-perfusion ratio $\left(\dot{V}_{A} / \dot{Q}\right)$, hypoxemia is primarily due to the $\dot{V}_{A} / \dot{Q}$ mismatch, which is more related to lung perfusion regulation impairment than to an increase in non-aerated tissue; therefore, lung recruitability is probably low $[8,9]$.
Patient inclusion, data collection and clinical management This study included all critically ill, invasively ventilated COVID-19 patients admitted from February 29th to May 15th, 2020 that underwent a two-PEEP CT scan on clinical indication. All patient had a positive polymerase chain reaction on nasopharyngeal swab specimens and fulfilled clinical criteria for severe COVID-19 pneumonia $[14,15]$. Clinical data were collected retrospectively from the electronic medical records. The Additional file 1 reports details on the two-PEEP CT clinical indications, image acquisition technique and analysis protocol. Patients were ventilated targeting tidal volumes of $6 \mathrm{~mL}$ per $\mathrm{kg}$ of predicted body weight, but increases were tolerated based on the driving pressure. The respiratory rate was titrated to maintain $\mathrm{pH}$ above 7.25 . The clinical PEEP level was decided by the treating physician, aimed at maintaining $\mathrm{PaO}_{2}>60 \mathrm{mmHg}$ with the lowest possible plateau pressure.

\section{Gas exchange and respiratory mechanics assessment}

Blood gas analyses and ventilation parameters were collected in all patients on the day of the CT scan. The ventilatory ratio [16] was computed as:

$$
\text { Ventilatory Ratio }=\frac{\text { minute ventilation }(\mathrm{ml} / \mathrm{min}) \times \mathrm{Pa}_{\mathrm{CO}_{2}}(\mathrm{mmHg})}{\text { predicted body weight }(\mathrm{kg}) \times 100 \times 37.5 \mathrm{mmHg}}
$$

To date, no specific recommendations are available concerning the optimal PEEP levels in invasively ventilated COVID-19 patients [10]. It has been suggested that COVID-19-associated ARDS might share common features with ordinary ARDS [11], in which the use of higher PEEP levels is frequently advocated [12], even if this strategy is not supported by the findings of recent trials [13]. Nevertheless, the pathophysiology of COVID19 seems to differ from that of ARDS [9] and limited physiological data is available on PEEP response in severe COVID-19 patients. We therefore conducted an observational study with the aim to investigate the effect of two levels of PEEP ( 8 and $16 \mathrm{cmH}_{2} \mathrm{O}$ ) on alveolar recruitment in severe COVID-19 patients. We hypothesized that the PEEP increase resulted in limited alveolar recruitment in COVID-19 patients.

\section{Methods}

This cohort study was carried out in a university-affiliated hospital in Genoa, Italy. The ethics review board approved the protocol of the study (Comitato Etico Regione Liguria, protocol n. 163/2020) and the need for written informed consent was waived for retrospectively collected data. According to local regulations, consent was delayed after discharge for prospectively collected data in unconscious patients.
The ventilatory ratio is an estimate of ventilation impairment and is known to correlate with physiologic dead-space fraction in COVID-19 patients [17]. A subgroup of patients underwent a PEEP test at 8 and 16 $\mathrm{cmH}_{2} \mathrm{O}$ at a $\mathrm{FiO}_{2}$ of 1.0 to estimate venous admixture and at a $\mathrm{FiO}_{2}$ of 0.5 , the latter value being arbitrarily chosen to explore the effects of $\mathrm{FiO}_{2}$ changes on oxygenation. All four possible $\mathrm{PEEP} / \mathrm{FiO}_{2}$ combinations were tested. Blood gas analyses and respiratory mechanics were assessed within $2 \mathrm{~h}$ from the CT scan and included estimation of venous admixture based on arterial and central venous blood gas samples (details in Additional file 1).

\section{Protocol for two-PEEP CT acquisition and analysis}

Patients received non-contrast chest CT scan at PEEP 8 $\mathrm{cmH}_{2} \mathrm{O}$ during expiratory breath-hold, then PEEP was increased to $16 \mathrm{cmH}_{2} \mathrm{O}$ and the $\mathrm{CT}$ scan repeated after around 1 min of ventilation with PEEP $16 \mathrm{cmH}_{2} \mathrm{O}$ and unchanged tidal volume, resulting in plateau pressures ranging from 25 to $35 \mathrm{cmH}_{2} \mathrm{O}$. No recruitment maneuver was performed. Lung parenchyma and vessel segmentations were obtained using multi-resolution convolutional neural networks [18], followed by manual refinement if necessary. Also, three regions of interests (ROIs) of equal lung tissue weight $[19,20]$ were obtained along the 
ventral-dorsal and craniocaudal axes. Lung was divided into hyper-, normally, poorly, and non-aerated compartments, according to conventional thresholds [21]. Alveolar recruitment was defined as the percent of lung weight accounted for by non-aerated tissue in which aeration was restored increasing PEEP from 8 to $16 \mathrm{cmH}_{2} \mathrm{O}$, i.e., previous physiologic studies in ARDS [21, 23-25]. All statistical analyses were performed in SPSS Statistics, Version 25.0 (IBM Corp., Armonk, NY, USA). Significance was assumed at two-tailed $p<0.05$.

$$
\text { Alveolar recruitment }=\left(\frac{\text { Nonaerated lung tissue }_{\text {PEEP } 8 \mathrm{~cm} \mathrm{H} \mathrm{H}_{2} \mathrm{O}}-\text { Nonaerated lung tissue }_{\text {PEEP } 16 \mathrm{~cm} \mathrm{H}_{2} \mathrm{O}}}{\text { Total lung weight }}\right) \times 100
$$

We defined patients in the fourth quartile of alveolar recruitment as "recruiters". The lung excess lung weight was calculated as percent difference of the CT-measured lung weight at $8 \mathrm{cmH}_{2} \mathrm{O}$ PEEP compared to the expected CT lung weight of a supine healthy patient, as follows:

\section{Results}

Population description

Of 88 patients invasively ventilated in the study period, 42 received a two-PEEP CT scan and were included in this analysis (patient inclusion flow in the Additional

$$
\text { Excess lung weight }(\%)=\frac{\text { Lung weight }}{\text { measured, PEEP } 8 \mathrm{~cm} \mathrm{H}_{2} \mathrm{O}-\text { Lung weight }_{\text {expected }}} \times 100 \text {, }
$$

where Lung weight expected $(\mathrm{g})=-1806.1+1633.7 \times$ height $(\mathrm{m})$ [22]. Dynamic lung strain was calculated as the ratio of the tidal volume to the end-expiratory gas volume measured by CT scan.

\section{Subgroup and sensitivity analyses}

To investigate the differences between phenotypes, we classified patients as "higher compliance" or "lower compliance" based on the respiratory system compliance on the day of CT scan assessed at the clinical PEEP level, with a cut-off of $40 \mathrm{ml} / \mathrm{cmH}_{2} \mathrm{O}$, the median value reported in a recent study [11]. As a sensitivity analysis, we computed alveolar recruitment as percent change of non- and poorly-aerated compartments [21]. We also investigated the time-dependency of alveolar recruitment and respiratory system compliance exploring their correlations with the time elapsed from the onset of symptoms and initiation of invasive ventilation.

\section{Statistical analysis}

The primary endpoint of the study was alveolar recruitment. Data are reported as median [interquartile range], if not otherwise specified. We compared data between groups with the Mann-Whitney $U$ or Fisher's exact test, as appropriate. Variables acquired at two PEEP levels were compared with the Wilcoxon signed-rank test. Correlations were sought using the Spearman's rho. We computed median differences (MD) with their 95\% confidence intervals (CI) using the Hodges-Lehman estimator. An a priori sample size calculation was not feasible due to the lack of data on quantitative CT analysis in COVID-19 patients, but our sample size was similar to file 1, eFigure 1); clinical characteristics on the day of CT are reported in Table 1. Gas-exchange and respiratory mechanics at both PEEP levels were analyzed in a subgroup of 20 patients, whose characteristics were comparable to those of the rest of the cohort (Additional file 1, eTable 1).

\section{Alveolar recruitment and effects of PEEP on CT parameters}

Alveolar recruitment was 2.7 [0.7-4.5] \% of the total lung weight or 39 [9-81] g; its distribution is reported in Fig. 1. Excess lung weight was 57 [24-75] \% or 528 [240-818] g and was correlated with the amount of non-aerated tissue ( $\rho=0.607, p<0.001$-Additional file 1 , eFigure 2). Ten patients were classified as "recruiters", having alveolar recruitment above the third quartile (4.5\%). We did not identify differences in the clinical characteristics of recruiters vs. non-recruiters (Table 1). Increasing PEEP from 8 to $16 \mathrm{cmH}_{2} \mathrm{O}$ resulted in a modest reduction in non-aerated tissue, paralleled by an increase in normally aerated and hyper-aerated tissue in both groups, while poorly aerated tissue decreased only in non-recruiters (Fig. 2 and Table 2). Figure 3 shows the distribution of lung aeration along the Hounsfield units scale at both PEEP levels. Non-aerated areas were predominantly located in dorsal and caudal regions (Additional file 1, eFigure 3). Lung dynamic strain was low and was further decreased by increasing PEEP (Table 2). The median PEEP-induced increase in lung gas content, proportional to the increase in lung static strain, was $403 \mathrm{ml}$ (95\% CI from 348 to $458 \mathrm{ml}$ ). Alveolar recruitment was not associated with disease severity as assessed by excess lung weight, $\mathrm{PaO}_{2} / \mathrm{FiO}_{2}$ ratio or respiratory system compliance 
Table 1 Patients' characteristics on the day of CT scan

\begin{tabular}{|c|c|c|c|c|}
\hline Parameter & All $(N=42)$ & Non-recruiters $(N=32)$ & Recruiters $(N=10)$ & $p$ \\
\hline Age, median [IQR], years & $63[58-67]$ & $64[58-67]$ & $65[58-66]$ & 0.782 \\
\hline Predicted body weight, median [IQR], kg & $70[61-73]$ & $70[61-71]$ & $72[70-75]$ & 0.102 \\
\hline Body mass index, median [IQR], $\mathrm{kg} / \mathrm{m}^{2}$ & $28[25-31]$ & $28[25-31]$ & 28 [26-29] & $>0.999$ \\
\hline Male sex, $N(\%)$ & $33(78.6)$ & $24(75.0)$ & $9(90.0)$ & 0.416 \\
\hline Time from symptoms onset, median [IQR], days & $23[13-28]$ & 23 [13-29] & 20 [17-25] & 0.631 \\
\hline Time from first confirmed swab, median [IQR], days & 15 [10-23] & 17 [9-24] & $13[10-20]$ & 0.738 \\
\hline Time from start of invasive ventilation, median [IQR], days & $9[4-13]$ & $9[4-14]$ & $7[3-11]$ & 0.328 \\
\hline \multicolumn{5}{|l|}{ Comorbidities } \\
\hline Hypertension, $N(\%)$ & $24(57.1)$ & $18(56.3)$ & $6(60.0)$ & $>0.999$ \\
\hline Cardiovascular disease, N (\%) & $5(11.9)$ & $3(9.4)$ & $2(20.0)$ & 0.577 \\
\hline Smoker, N (\%) & $1(2.4)$ & $1(3.1)$ & $0(0.0)$ & $>0.999$ \\
\hline Former smoker, $N(\%)$ & $5(11.9)$ & $5(15.6)$ & $0(0.0)$ & 0.315 \\
\hline Chronic kidney failure, $N(\%)$ & $1(2.4)$ & $1(3.1)$ & $0(0.0)$ & $>0.999$ \\
\hline Diabetes, $N(\%)$ & $5(11.9)$ & $5(15.6)$ & $0(0.0)$ & 0.315 \\
\hline Obesity, N (\%) & $11(26.2)$ & $8(25.0)$ & $3(30.0)$ & $>0.999$ \\
\hline \multicolumn{5}{|l|}{ Ventilator settings } \\
\hline Tidal volume, median [IQR], ml/kg PBW & $7.2[6.3-7.9]$ & $7.3[6.3-8.0]$ & $6.9[6.2-7.6]$ & 0.494 \\
\hline Respiratory rate, median [IQR], 1/min & 19 [17-25] & 18 [16-25] & $22[19-24]$ & 0.273 \\
\hline PEEP, median [IQR], $\mathrm{cmH}_{2} \mathrm{O}$ & $10[8-12]$ & $10[8-12]$ & 10 [8-13] & 0.988 \\
\hline Plateau pressure, median [IQR], $\mathrm{cmH}_{2} \mathrm{O}$ & $24[21-28]$ & 24 [22-28] & $24[20-27]$ & 0.782 \\
\hline $\mathrm{FiO}_{2}$, median $[\mathrm{IQR}]$ & $0.60[0.50-0.70]$ & $0.68[0.60-0.70]$ & $0.55[0.50-0.65]$ & 0.138 \\
\hline Respiratory system compliance, median [IQR], $\mathrm{ml} / \mathrm{cmH}_{2} \mathrm{O}$ & $36[29-50]$ & $35[29-50]$ & $40[35-45]$ & 0.631 \\
\hline \multicolumn{5}{|l|}{ Blood gas analysis } \\
\hline $\mathrm{pH}$, median [IQR] & $7.43[7.36-7.48]$ & $7.42[7.35-7.47]$ & $7.46[7.43-7.49]$ & 0.052 \\
\hline $\mathrm{PaO}_{2}$, median [IQR], mmHg & 73 [64-91] & $73[65-92]$ & $69[64-86]$ & 0.475 \\
\hline $\mathrm{PaCO}_{2}$, median [IQR], mmHg & $48[43-56]$ & $51[44-58]$ & $41[36-51]$ & 0.052 \\
\hline $\mathrm{PaO}_{2} / \mathrm{FiO}_{2}$, median [IQR], mmHg & 123 [100-160] & 123 [98-155] & 139 [103-205] & 0.494 \\
\hline Lactate, median [IQR], mmol/L & $1.1[0.8-1.8]$ & $1.2[0.8-2.0]$ & $1.1[1.0-1.6]$ & 0.782 \\
\hline Ventilatory ratio & $1.8[1.5-2.4]$ & $2.0[1.5-2.6]$ & $1.8[1.6-1.8]$ & 0.494 \\
\hline \multicolumn{5}{|l|}{ Blood analyses } \\
\hline D-dimer, median [IQR], ug/L & 1647 [1048-4426] & 1618 [938-4195] & 1754 [1304-4426] & 0.695 \\
\hline C reactive protein, median [IQR], mg/L & $42[17-108]$ & 44 [19-110] & $41[17-60]$ & 0.531 \\
\hline Procalcitonin, median $[\mathrm{IQR}], \mathrm{ug} / \mathrm{L}$ & $0.21[0.09-0.97]$ & $0.25[0.09-1.44]$ & $0.21[0.07-0.33]$ & 0.423 \\
\hline Interleukin-6, median [IQR], ng/L & $127[55-387]$ & 134 [55-339] & $112[16-453]$ & 0.873 \\
\hline Creatinine, median [IQR], mg/dL & $0.9[0.7-1.7]$ & $0.9[0.6-1.7]$ & $1.0[0.7-1.5]$ & 0.652 \\
\hline \multicolumn{5}{|l|}{ Hemodynamics } \\
\hline Heart rate, median [IQR], 1/min & $82[70-100]$ & 85 [72-103] & $73[68-90]$ & 0.494 \\
\hline Mean arterial pressure, median [IQR], $\mathrm{mmHg}$ & 82 [73-93] & $83[77-102]$ & 80 [73-85] & 0.551 \\
\hline Ventilator-associated pneumonia, $N(\%)$ & $12(28.6)$ & $11(34.3)$ & $1(10.0)$ & 0.233 \\
\hline
\end{tabular}

Gas exchange and ventilator settings measured at the clinical PEEP level

$I Q R$ interquartile range, $P B W$ predicted body weight, $P E E P$ positive end-expiratory pressure, ICU intensive care unit

(Additional file 1, eFigure 4). We did not observe correlations between alveolar recruitment or excess lung mass and inflammatory and thrombophilia markers (Additional file 1, eTable 2). Alveolar recruitment defined as change in the sum of poorly- and non-aerated compartments was 4.3 [2.9-6.1] \% of the total lung weight and no differences were observed in lower vs. higher compliance groups (4.2 [2.6-6.0] \% vs. $4.4[3.6-6.6] \%, p=0.402)$.

\section{Data on gas exchange and respiratory mechanics at two PEEP levels}

As illustrated in Fig. 4, in patients with available data on gas-exchange and respiratory mechanics at two PEEP levels $(\mathrm{N}=20)$, incrementing PEEP from 8 to $16 \mathrm{cmH}_{2} \mathrm{O}$ increased the $\mathrm{PaO}_{2}$ when $\mathrm{FiO}_{2}=0.5$ (MD $24 \mathrm{mmHg}$, 95\% CI from 12 to $51 \mathrm{mmHg}, p=0.003$ ), but not when $\mathrm{FiO}_{2}=1.0(\mathrm{MD} 7 \mathrm{mmHg}, 95 \% \mathrm{CI}$ from -12 


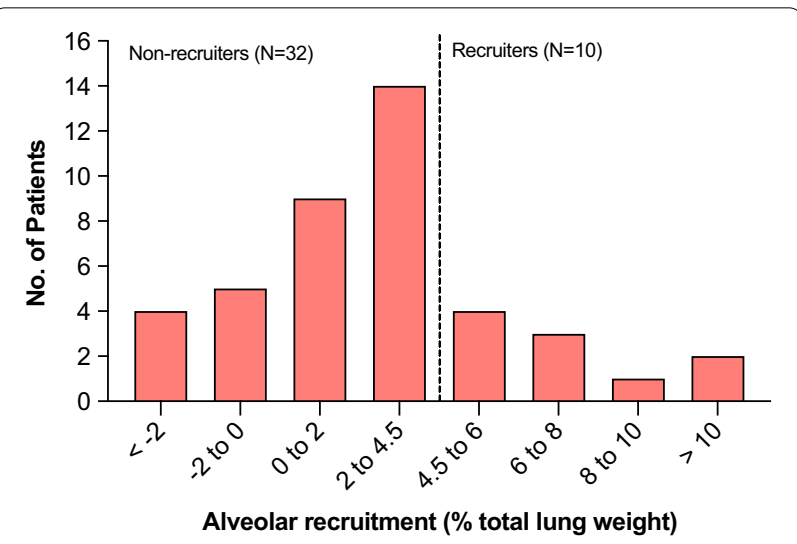

Fig. 1 Distribution of alveolar recruitment. The dashed line represents the boundary of the third quartile (4.5\%), defining the "recruiters" group

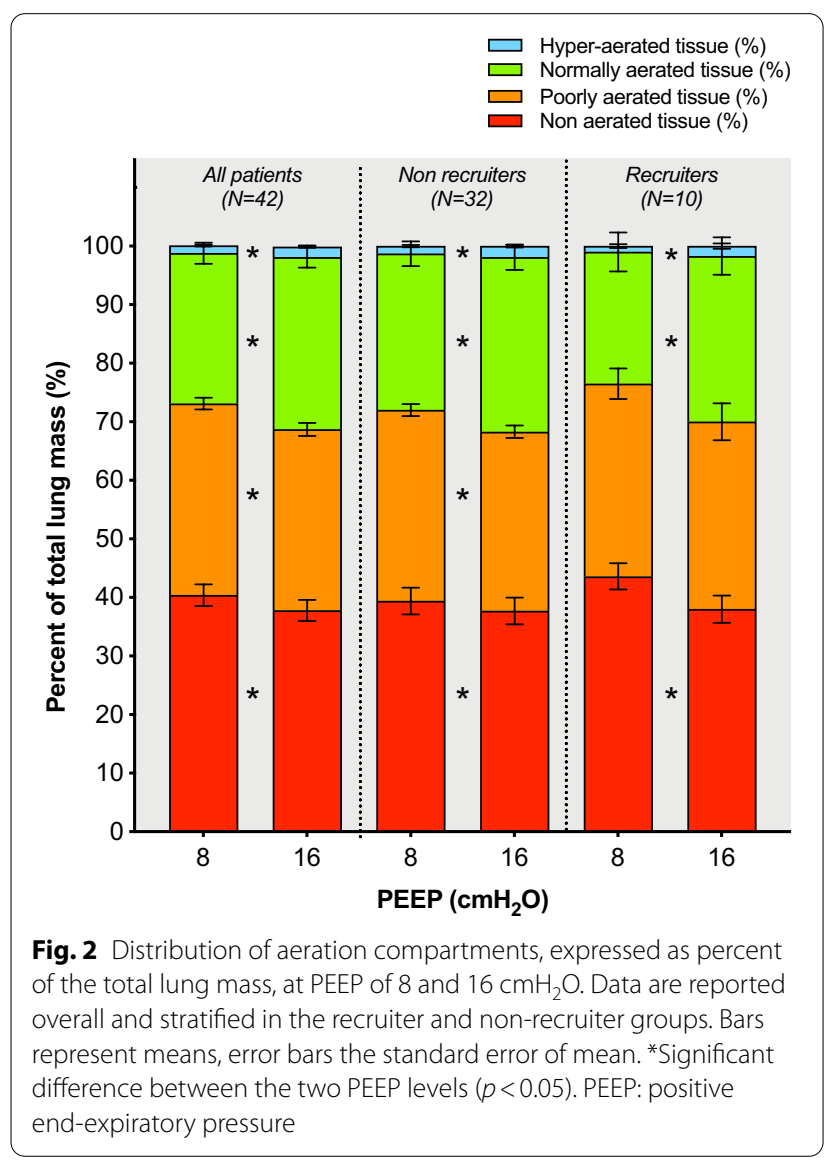

to $49 \mathrm{mmHg}, p=0.257)$. Maintaining PEEP at $8 \mathrm{cmH}_{2} \mathrm{O}$, increasing $\mathrm{FiO}_{2}$ from 0.5 to 1.0 increased the $\mathrm{PaO}_{2}$ (MD $103 \mathrm{mmHg}, 95 \% \mathrm{CI}$ from 55 to $156 \mathrm{mmHg}, p<0.001)$. Increasing PEEP from 8 to $16 \mathrm{cmH}_{2} \mathrm{O}$ slightly reduced the venous admixture (MD - 3.5\%, 95\% CI from - 6.2\% to $-0.4 \%, p=0.027)$ and the ventilatory ratio $(\mathrm{MD}-0.1$,
95\% CI from -0.3 to $-0.1, p=0.003$, Additional file 1 , eFigure 5), but decreased the respiratory system compliance $\left(\mathrm{MD}-9 \mathrm{ml} / \mathrm{cmH}_{2} \mathrm{O}, 95 \% \mathrm{CI}\right.$ from -12 to $-6 \mathrm{ml} /$ $\left.\mathrm{cmH}_{2} \mathrm{O}, p<0.001\right)$. Improvement of oxygenation and venous admixture were not associated with alveolar recruitment (Additional file 1, eFigure 6).

\section{Characteristics of patients with higher versus lower compliance}

Patients in the lower compared to higher compliance group had a longer time elapsed from the onset of symptoms and were ventilated with lower tidal volumes and higher plateau pressures (Additional file 1, eTable 3). Alveolar recruitment was similar in lower vs. higher compliance groups (2.5 [0.6-4.4] \% vs. 3.0 [0.8-4.7] \%, $p=0.780)$. Excess lung weight was similar in lower vs. higher compliance groups (52 [21-73] \% vs. 57 [28-80] $\%, p=0.799)$.

\section{Time-dependency of alveolar recruitment and respiratory system compliance}

Time from the onset of symptoms and onset of invasive ventilation was similar in recruiters versus non-recruiters (Table 1), while patients in the lower compliance group had a longer time elapsed from the first confirmed swab and onset of symptoms (Additional file 1, eTable 3 ). The respiratory system compliance had a negative correlation with the days elapsed from the onset of symptoms $(\rho=-$ 0.407, $p=0.007$ ) but not with the duration of invasive ventilation $(\rho=-0.134, p=0.397)$. Alveolar recruitment did not correlate with the time elapsed from the onset of symptoms $(\rho=0.058, p=0.716)$ nor with the duration of invasive ventilation $(\rho=-0.013, p=0.935)$.

\section{Discussion}

The main findings of this study were that, in critically ill mechanically ventilated patients with severe COVID19 pneumonia, alveolar recruitment induced by changes of PEEP from $8 \mathrm{cmH} 2 \mathrm{O}$ to $16 \mathrm{cmH} 2 \mathrm{O}$ was: (1) minimal and independent of the respiratory system compliance; (2) prevalent in the dependent and caudal lung regions; (3) not correlated with the excess lung weight; and (4) not associated with changes in gas-exchange, respiratory mechanics and laboratory parameters. Higher PEEP improved oxygenation at $\mathrm{FiO}_{2} 0.5$ but not 1.0 and decreased respiratory system compliance.

Patients included in the present study had severe hypoxemic respiratory failure at ICU admission and at the time of CT scan. We assessed alveolar recruitment as changes in the non-aerated compartment, using classically adopted CT attenuation thresholds [21, 23-25]. The two levels of PEEP selected in the present study, i.e., 8 and $16 \mathrm{cmH}_{2} \mathrm{O}$, were the boundaries of the range 
Table 2 Quantitative CT analysis parameters

\begin{tabular}{|c|c|c|c|c|c|c|c|c|c|}
\hline \multirow[t]{2}{*}{ Parameter } & \multicolumn{3}{|l|}{ All $(N=42)$} & \multicolumn{3}{|c|}{ Non-recruiters $(N=32)$} & \multicolumn{3}{|c|}{ Recruiters $(N=10)$} \\
\hline & PEEP $8 \mathrm{cmH}_{2} \mathrm{O}$ & $\begin{array}{l}\text { PEEP } 16 \\
\mathrm{cmH}_{2} \mathrm{O}\end{array}$ & $p$ & PEEP $8 \mathrm{cmH}_{2} \mathrm{O}$ & $\begin{array}{l}\text { PEEP } 16 \\
\mathrm{cmH}_{2} \mathrm{O}\end{array}$ & $p$ & PEEP $8 \mathrm{cmH}_{2} \mathrm{O}$ & $\begin{array}{l}\text { PEEP } 16 \\
\mathrm{cmH}_{2} \mathrm{O}\end{array}$ & $p$ \\
\hline $\begin{array}{l}\text { Total lung } \\
\text { volume (ml) }\end{array}$ & $\begin{array}{l}3076[2610- \\
3810]\end{array}$ & $\begin{array}{l}3461 \text { [2982- } \\
4190]\end{array}$ & $<0.001^{*}$ & $\begin{array}{l}3120[2687- \\
3727]\end{array}$ & $\begin{array}{l}3575[3107- \\
4150]\end{array}$ & $<0.001^{*}$ & $\begin{array}{l}2619[2331- \\
3907]\end{array}$ & $\begin{array}{l}2953[2454- \\
4645]\end{array}$ & $0.005^{*}$ \\
\hline $\begin{array}{l}\text { Total lung } \\
\text { weight (g) }\end{array}$ & $\begin{array}{l}1515[1295- \\
1811]\end{array}$ & $\begin{array}{l}1539[1336- \\
1852]\end{array}$ & 0.866 & $\begin{array}{l}1504[1274- \\
2091]\end{array}$ & $\begin{array}{l}1520[1322- \\
2126]\end{array}$ & 0.080 & $\begin{array}{l}1532[1302- \\
1773]\end{array}$ & $\begin{array}{l}1455[1244- \\
1728]\end{array}$ & 0.116 \\
\hline $\begin{array}{l}\text { Excess lung } \\
\text { weight (\%) }\end{array}$ & $56.6[24.0-74.8]$ & & & $56.7[23.2-90.5]$ & & & $\begin{array}{l}55.0[26.3- \\
59.59]\end{array}$ & & \\
\hline $\begin{array}{l}\text { Gas volume } \\
\text { (ml) }\end{array}$ & $\begin{array}{l}1360[1064- \\
2118]\end{array}$ & $\begin{array}{l}1858[1301- \\
2599]\end{array}$ & $<0.001^{*}$ & $\begin{array}{l}1448[1105- \\
2159]\end{array}$ & $\begin{array}{l}1931[1459- \\
2583]\end{array}$ & $<0.001^{*}$ & $\begin{array}{l}1216[701- \\
2115]\end{array}$ & $\begin{array}{l}1540[1085- \\
2957]\end{array}$ & $0.005^{*}$ \\
\hline $\begin{array}{l}\text { Mean attenua- } \\
\text { tion }(\mathrm{HU})\end{array}$ & $\begin{array}{l}-526[-591-- \\
329]\end{array}$ & $\begin{array}{l}-565[-637-- \\
404]\end{array}$ & $<0.001^{*}$ & $\begin{array}{l}-549[-616-- \\
333]\end{array}$ & $\begin{array}{l}-581[-644-- \\
405]\end{array}$ & $<0.001^{*}$ & $\begin{array}{l}-434[-541-- \\
301]\end{array}$ & $\begin{array}{l}-539[-634-- \\
379]\end{array}$ & $0.005^{*}$ \\
\hline $\begin{array}{l}\text { Hyper-aerated } \\
\text { mass (g) }\end{array}$ & $14[7-28]$ & 23 [12-39] & $<0.001^{*}$ & $17[8-29]$ & 26 [13-39] & $<0.001^{*}$ & $12[5-17]$ & $17[8-43]$ & $0.005^{*}$ \\
\hline $\begin{array}{l}\text { Normally aer- } \\
\text { ated mass (g) }\end{array}$ & 367 [259-465] & $424[347-528]$ & $<0.001^{*}$ & $375[307-462]$ & 440 [366-532] & $<0.001^{*}$ & $\begin{array}{l}331[190.9- \\
504.4]\end{array}$ & $\begin{array}{l}383[267.4- \\
520.3]\end{array}$ & $0.005^{*}$ \\
\hline $\begin{array}{l}\text { Poorly aerated } \\
\text { mass (g) }\end{array}$ & $504[391-671]$ & $487[346-673]$ & $<0.001^{*}$ & 504 [388-687] & 496 [349-683] & $0.001^{*}$ & $\begin{array}{c}477 \text { [393.9- } \\
587.5]\end{array}$ & $\begin{array}{l}433[328.1- \\
580.8]\end{array}$ & 0.093 \\
\hline $\begin{array}{l}\text { Non aerated } \\
\text { mass }(\mathrm{g})\end{array}$ & $625[377-810]$ & $576[354-775]$ & $<0.001^{*}$ & $564[375-785]$ & 581 [350-854] & $0.014^{*}$ & $\begin{array}{l}737[515.7- \\
819.1]\end{array}$ & $\begin{array}{l}573[435.2- \\
\quad 710.4]\end{array}$ & $0.005^{*}$ \\
\hline $\begin{array}{l}\text { Dynamic lung } \\
\text { strain }\end{array}$ & $0.33[0.23-0.46]$ & $0.26[0.19-0.35]$ & $<0.001^{*}$ & $0.33[0.24-0.43]$ & $0.25[0.19-0.3]$ & $<0.001^{*}$ & $0.41[0.22-0.63]$ & $0.33[0.16-0.45]$ & $<0.005^{*}$ \\
\hline
\end{tabular}

Data are presented as median [interquartile range]

$P E E P$ positive end-expiratory pressure, $H U$ Hounsfield Units, $I Q R$ interquartile range, $\mathrm{Cl}$ confidence interval

*Signigicant difference between PEEP levels, $p<0.05$

of PEEP received by most COVID-19 patients [26], and similar to previous studies investigating alveolar recruitment in ARDS, where 5 and $15 \mathrm{cmH}_{2} \mathrm{O}$ were used [25]. The lower level of PEEP in our study was set at $8 \mathrm{cmH}_{2} \mathrm{O}$ due to safety concerns related to the reduction in PEEP to $5 \mathrm{cmH}_{2} \mathrm{O}$ in severely hypoxemic COVID-19 patients.

Spontaneously breathing healthy subjects have an average lung weight of around $930 \mathrm{~g}$ [22]. In our cohort, lung weight was $1500 \mathrm{~g}$ and end-expiratory gas volume $1360 \mathrm{ml}$, values similar to those reported in studies on ARDS not related to COVID-19 [21, 25]. The gas volume was similar to that reported in a recent study, showing that when classical ARDS was compared at similar $\mathrm{PaO}_{2} / \mathrm{FiO}_{2}$ or compliance, the gas volume was higher in COVID-19 [5]. This is in line with a recent study comparing twenty-seven COVID-19 patients with an historical cohort of classical ARDS [11]. However, another study comparing COVID-19 ARDS with ARDS from other causes concluded that, when patients were matched based on their $\mathrm{PaO}_{2} / \mathrm{FiO}_{2}$ ratio or respiratory system compliance, the two pathologies had substantial differences with potential implications to the optimal ventilator management [5]. In patients with classical ARDS, the overall lung weight is increased compared to normal patients, due to increased edema distributed along a ventral-dorsal gradient [27]. This leads to increased pressures acting on the dependent lung regions and progressive atelectasis formation $[27,28]$. The application of PEEP counterbalances the effects of increased superimposed pressure on most dependent alveoli [29], keeping them open and improving respiratory system compliance and gas-exchange. The median amount of alveolar recruitment from 8 to $16 \mathrm{cmH}_{2} \mathrm{O}$ PEEP in our COVID19 cohort was less than $3 \%$ of the total lung mass. This value is lower than the lung tissue recruited from 5 to $15 \mathrm{cmH}_{2} \mathrm{O}$ PEEP in classical ARDS, which ranged from 8 to $15 \%$ of lung weight $[21,25]$ or $21 \%$ of lung volume [23] in early studies. Moreover, these studies reported high inter-subject variability in classical ARDS, while we observed a homogeneously low recruitment potential in our cohort. In line with our results, previous studies found that PEEP-induced alveolar recruitment was lower in patients with primary as compared to a secondary insult to the lung [30]. In a study in ten COVID-19 patients measuring recruitment from 5 to $15 \mathrm{cmH}_{2} \mathrm{O}$ PEEP with electric impedance tomography, the recruited lung volume was around $300 \mathrm{ml}$ with high inter-individual variability [31]. However, it is difficult to compare this value to our results because of the different imaging technique adopted, analyzing only one juxta-diaphragmatic slice. The application of PEEP $16 \mathrm{cmH}_{2} \mathrm{O}$ also increased hyperaeration, especially in presence of less excess lung 


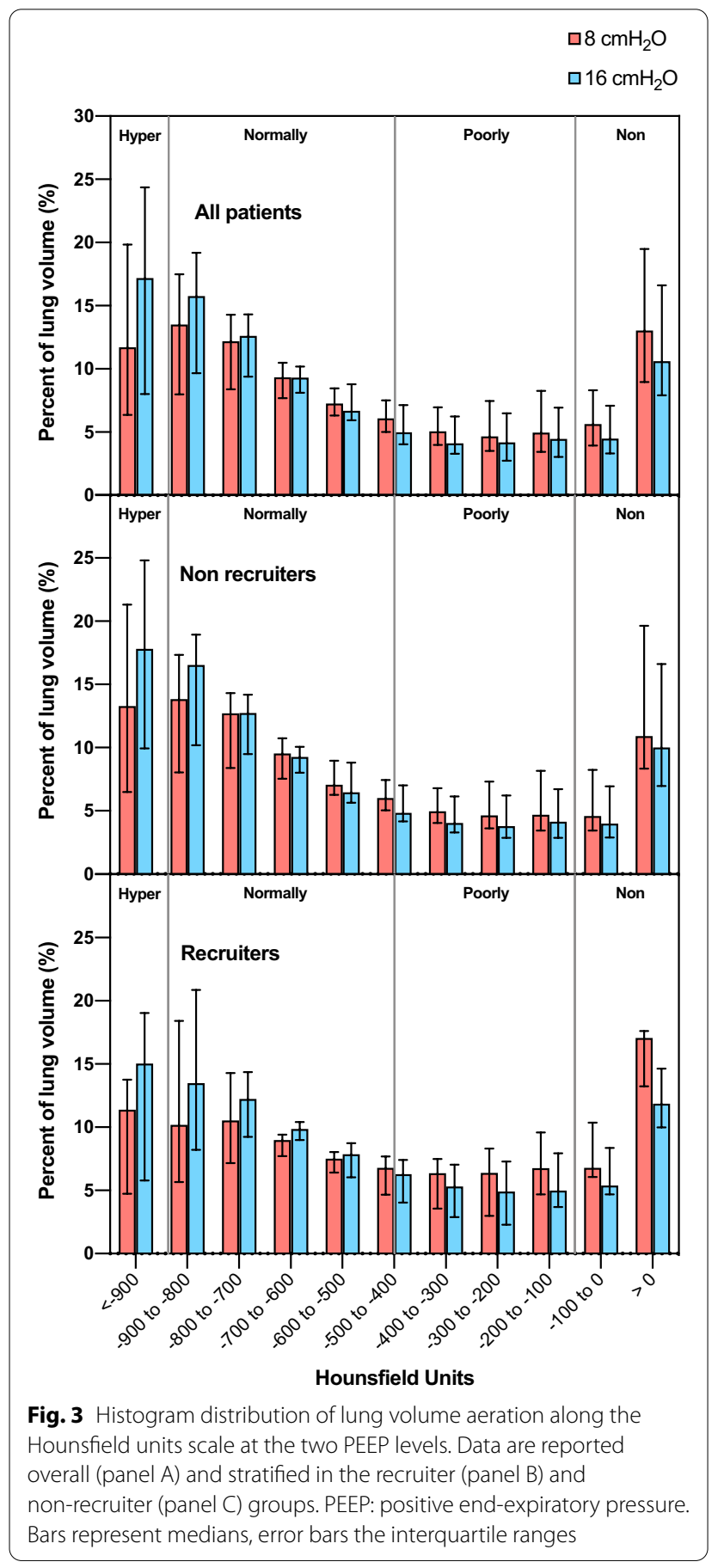

weight, as reported in classical ARDS patients [23]. As a consequence, the increase in PEEP from 8 to 16 $\mathrm{cmH}_{2} \mathrm{O}$ yielded a worsening of the respiratory system compliance in our cohort of COVID-19 patients. Alveolar recruitment was not associated with higher levels of inflammatory markers, D-dimer and respiratory system compliance.
These findings support the concept that PEEP might improve oxygenation in COVID-19 by altering the $\dot{V} / \dot{Q}$ matching in areas with low $\dot{V}_{A} / \dot{Q}$, rather than through recruitment. This suggests caution in applying PEEP levels higher than those strictly necessary to maintain oxygenation. We observed a decrease in respiratory system compliance among patients at more advanced stages of the disease, not reflected by increased recruitment. This is compatible with a natural history of the disease based on fibrotic mechanisms, rather than worsening of edema. Our findings suggest that COVID-19 pneumonia acts as a typical primary pneumonia [32], as also confirmed by autopsy findings, which reported injury in the alveolar epithelial cells, hyaline membrane formation, and hyperplasia of type II pneumocytes, diffuse alveolar damage and consolidation due to fibroblastic proliferation with extracellular matrix and fibrin forming clusters in airspaces and capillary vessel [33]. We speculate that, differently from classical ARDS, in COVID-19 pneumonia, the non-aerated lung regions are poorly recruitable due to the fact that they do not represent atelectasis, but alveolar spaces substituted by fibrosis and mucinous filling, cellular debris and necrotic tissue reflecting pneumo-and vascular lysis [34-36].

Some limitations of our study should be addressed. In our center, CT scan and evaluation of PEEP was routinely performed in a high proportion of patients with COVID19 pneumonia for clinical purposes, but only when CT was indicated and in sufficiently stable patients. The main reasons for exclusion were clinical instability and need for contrast-enhanced CT. The timing of CT scans was based on clinical indication, resulting in heterogeneity of included patients, and we cannot rule out that, in a proportion of patient, bacterial co-infection might have played a role in defining the radiological findings and the response to PEEP [37]. However, this is representative of the population of a COVID-19 ICU. Only two arbitrary levels of PEEP were investigated for technical reasons and patient safety concerns. While we cannot exclude that different ventilator setting or the addition of a recruitment maneuver may have led to different results, previous studies reported that the response to PEEP at two low and moderate PEEP levels correlated with the maximal lung recruitment achievable at higher PEEP [25]. Moreover, venous admixture was estimated from central venous line blood samples, not a pulmonary artery catheter.

\section{Conclusions}

In critically ill patients with severe COVID-19 pneumonia, increasing PEEP from $8 \mathrm{cmH}_{2} \mathrm{O}$ to $16 \mathrm{cmH}_{2} \mathrm{O}$ did not lead to major alveolar recruitment while worsened respiratory mechanics. This suggests limiting PEEP strictly 

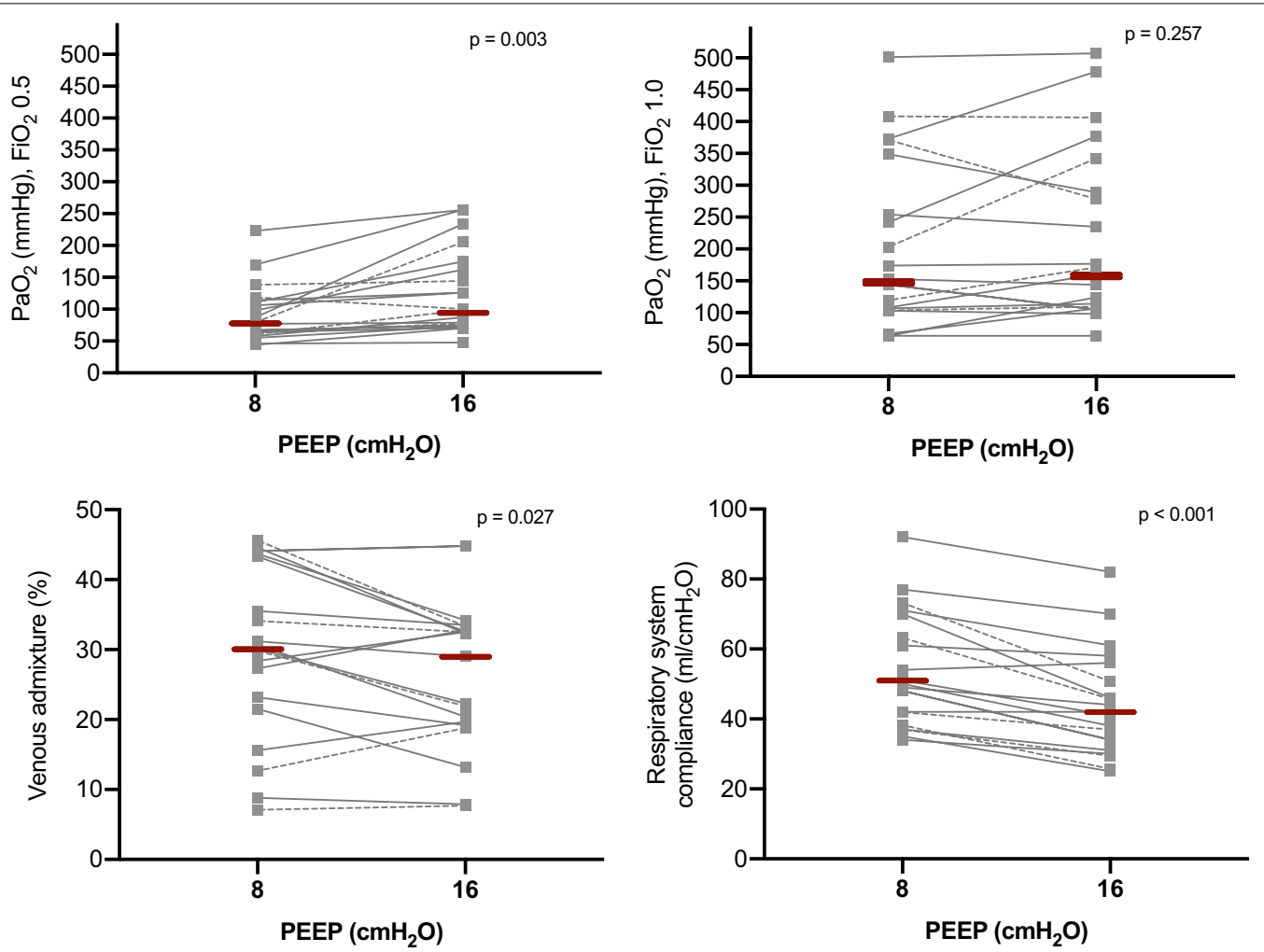

Fig. 4 Gas-exchange and respiratory mechanics data at PEEP of 8 and $16 \mathrm{cmH}_{2} \mathrm{O}$. Gray squares and lines represent individual patient data, red bars the median value. Dashed lines represent patients in the recruiter group, solid lines the non-recruiter group. PEEP: positive end-expiratory pressure

to those levels necessary to maintain oxygenation, thus avoiding the use of higher PEEP levels. Lung imaging techniques might be considered in the next future to better assess clinical alterations in critically ill patients with COVID-19 pneumonia.

\section{Supplementary Information}

The online version contains supplementary material available at https://doi. org/10.1186/s13054-021-03477-w.

Additional file 1. Study details and additional analyses.

\section{Acknowledgements}

We are grateful for the efforts of the GECOVID (GEnoa COVID-19) group: Angelo Gratarola, Maurizio Loconte, Alexandre Molin, Giulia Orefice, Francesca Iannuzzi, Federico Costantino, Dario Battioni, Giulio Bovio, Gerolama Buconte, Alessandro Casaleggio, Giuseppe Cittadini, Luca Dogliotti, Veronica Giasotto, Maria Pigati, Elena Santacroce, Federico Zaottini, Chiara Dentone, Lucia Taramasso, Laura Magnasco, Alberto Valbusa, Matilde Bastianello.

\section{Authors' contributions}

LB had full access to all of the data in this study and takes responsibility for the integrity of the data and the accuracy of the data analysis and also responsible for statistical analysis. LB, PP, NP, PRMR and MC were responsible for concept and design. $L B, L M, C R$, JH, SG, YX, DB, IB, GM, SS, AV, DRG, MB, PRMR, LC, NP and $\mathrm{PP}$ were responsible for acquisition, analysis and interpretation of data. $L B, C R, P P, N P, P R M R$ and $M C$ were responsible for manuscript writing. PP, NP,
PRMR and MC were responsible for supervision. All authors read and approved the final version of the manuscript.

\section{Funding}

This research was partly funded by the Conselho Nacional de Desenvolvimento Científico e Tecnológico (CNPq) (401700/2020-8), and Fundação Carlos Chagas Filho de Amparo à Pesquisa do Estado do Rio de Janeiro (E-26/210.181/ 2020). The funders had no role in the study design nor manuscript preparation.

\section{Availability of data and materials}

Dataset available from the corresponding author upon reasonable request.

Ethics approval and consent to participate

The ethics review board approved the protocol of the study (Comitato Etico Regione Liguria, protocol no. 163/2020).

\section{Consent to participate}

The need for written informed consent was waived for retrospectively collected data. According to local regulations, consent was delayed after discharge for prospectively collected data in unconscious patients.

\section{Consent for publication}

Not applicable.

\section{Code availability}

Not applicable.

\section{Competing interests}

Dr. Bassetti reports personal fees and other from Angelini, personal fees and other from AstraZeneca, other from Bayer, personal fees and other from Cubist, personal fees and other from Pfizer, personal fees and other from Menarini, 
personal fees and other from MSD, other from Nabriva, other from Paratek, other from Roche, other from Shionogi, other from Tetraphase, other from The Medicine Company, personal fees and other from Astellas Pharma Inc., personal fees from Gilead Sciences, personal fees from Teva, personal fees from Novartis, grants from Ranbaxy, personal fees from Correvio, personal fees from Molteni, personal fees from Thermo Fisher, outside the submitted work. Dr. Herrmann is cofounder and shareholder in OscillaVent, Inc, and consultant for ZOLL Medical Corporation, both outside the submitted work. Dr. Giacobbe reports personal fees from Stepstone Pharma GmbH, personal fees from MSD Italia, personal fees from Correvio Italia, outside the submitted work. Dr. Rocco reports personal fees from SANOFI as a DSMB member. All other authors declared no conflict of interest.

\section{Author details}

${ }^{1}$ Department of Surgical Sciences and Integrated Diagnostics (DISC), University of Genoa, Viale Benedetto XV 16, Genoa, Italy. ${ }^{2}$ Anesthesia and Intensive Care, Ospedale Policlinico San Martino, IRCCS Per L'Oncologia e le Neuroscienze, Genoa, Italy. ${ }^{3}$ Department of Biomedical Engineering, Harvard Medical School, Boston, MA, USA. ${ }^{4}$ Department of Radiology, Harvard Medical School, Boston, MA, USA. ${ }^{5}$ Department of Radiology, Perelman School of Medicine, University of Pennsylvania, Philadelphia, PA, USA. ${ }^{6}$ Radiology Department, Ospedale Policlinico San Martino, IRCCS Per L'Oncologia e le Neuroscienze, Genoa, Italy. ${ }^{7}$ Infectious Diseases Unit, Ospedale Policlinico San Martino, IRCCS Per L'Oncologia e le Neuroscienze, Genoa, Italy. ${ }^{8}$ Department of Health Sciences (DISSAL), University of Genoa, Genoa, Italy. ${ }^{9}$ Laboratory of Pulmonary Investigation, Carlos Chagas Filho Institute of Biophysics, Federal University of Rio de Janeiro, Rio de Janeiro, Brazil. ${ }^{10}$ Department of Anesthesiology and Critical Care, Perelman School of Medicine, University of Pennsylvania, Philadelphia, PA, USA.

Received: 25 November 2020 Accepted: 20 January 2021 Published online: 24 February 2021

\section{References}

1. Zhu N, Zhang D, Wang W, Li X, Yang B, Song J, et al. A novel coronavirus from patients with pneumonia in China, 2019. N Engl J Med. 2020;382:727-33.

2. Huang C, Wang Y, Li X, Ren L, Zhao J, Hu Y, et al. Clinical features of patients infected with 2019 novel coronavirus in Wuhan, China. Lancet Lond Engl. 2020;395:497-506

3. Ren L-L, Wang Y-M, Wu Z-Q, Xiang Z-C, Guo L, Xu T, et al. Identification of a novel coronavirus causing severe pneumonia in human: a descriptive study. Chin Med J (Engl). 2020;133:1015-24.

4. ARDS Definition Task Force, Ranieri VM, Rubenfeld GD, Thompson BT, Ferguson ND, Caldwell E, et al. Acute respiratory distress syndrome: the Berlin Definition. JAMA. 2012;307:2526-33.

5. Chiumello D, Busana M, Coppola S, Romitti F, Formenti P, Bonifazi M, et al. Physiological and quantitative CT-scan characterization of COVID-19 and typical ARDS: a matched cohort study. Intensive Care Med. 2020. https:// doi.org/10.1007/s00134-020-06281-2.

6. Marini JJ, Gattinoni L. Management of COVID-19 Respiratory Distress. JAMA. 2020;323:2329.

7. Inui S, Fujikawa A, Jitsu M, Kunishima N, Watanabe S, Suzuki Y, et al. Chest CT findings in cases from the cruise ship "diamond princess" with coronavirus disease 2019 (COVID-19). Radiol Cardiothorac Imaging. 2020;2:e200110

8. Gattinoni L, Chiumello D, Caironi P, Busana M, Romitti F, Brazzi L, et al. COVID-19 pneumonia: different respiratory treatments for different phenotypes? Intensive Care Med. 2020.

9. Robba C, Robba C, Battaglini D, Ball L, Patroniti N, Loconte M, et al. Distinct phenotypes require distinct respiratory management strategies in severe COVID-19. Respir Physiol Neurobiol. 2020;103455.

10. Alhazzani W, Møller MH, Arabi YM, Loeb M, Gong MN, Fan E, et al. Surviving sepsis campaign: guidelines on the management of critically ill adults with coronavirus disease 2019 (COVID-19). Crit Care Med. 2020:48:e440-69.

11. Grasselli G, Tonetti T, Protti A, Langer T, Girardis M, Bellani G, et al. Pathophysiology of COVID-19-associated acute respiratory distress syndrome: a multicentre prospective observational study. Lancet Respir Med. 2020.
12. Fan E, Del Sorbo L, Goligher EC, Hodgson CL, Munshi L, Walkey AJ, et al. An Official American Thoracic Society/European Society of Intensive Care Medicine/Society of Critical Care Medicine Clinical Practice Guideline: Mechanical Ventilation in Adult Patients with Acute Respiratory Distress Syndrome. Am J Respir Crit Care Med. 2017;195:1253-63.

13. Ball L, Serpa Neto A, Trifiletti V, Mandelli M, Firpo I, Robba C, et al. Effects of higher PEEP and recruitment manoeuvres on mortality in patients with ARDS: a systematic review, meta-analysis, meta-regression and trial sequential analysis of randomized controlled trials. Intensive Care Med Exp. 2020;8:39.

14. Wu Z, McGoogan JM. Characteristics of and Important Lessons from the coronavirus disease 2019 (COVID-19) outbreak in china: summary of a report of 72314 cases from the Chinese Center for Disease Control and Prevention. JAMA. 2020;323:1239-42.

15. Berlin DA, Gulick RM, Martinez FJ. Severe covid-19. N Engl J Med. 2020;383:2451-60.

16. Sinha P, Fauvel NJ, Singh S, Soni N. Ventilatory ratio: a simple bedside measure of ventilation. Br J Anaesth. 2009;102:692-7.

17. Diehl J-L, Peron N, Chocron R, Debuc B, Guerot E, Hauw-Berlemont C, et al. Respiratory mechanics and gas exchanges in the early course of COVID-19 ARDS: a hypothesis-generating study. Ann Intensive Care. 2020;10:95

18. Gerard SE, Herrmann J, Kaczka DW, Musch G, Fernandez-Bustamante A, Reinhardt JM. Multi-resolution convolutional neural networks for fully automated segmentation of acutely injured lungs in multiple species. Med Image Anal. 2020;60:101592.

19. Protti $A$, lapichino GE, Milesi M, Melis V, Pugni $P$, Comini B, et al. Validation of computed tomography for measuring lung weight. Intensive Care Med Exp. 2014;2:31

20. Güldner A, Braune A, Ball L, Silva PL, Samary C, Insorsi A, et al. Comparative effects of volutrauma and atelectrauma on lung inflammation in experimental acute respiratory distress syndrome. Crit Care Med. 2016:44:e854-865.

21. Malbouisson LM, Muller J-C, Constantin J-M, Lu Q, Puybasset L, Rouby $\mathrm{J}$-J, et al. Computed tomography assessment of positive end-expiratory pressure-induced alveolar recruitment in patients with acute respiratory distress syndrome. Am J Respir Crit Care Med. 2001;163:1444-50.

22. Cressoni M, Gallazzi E, Chiurazzi C, Marino A, Brioni M, Menga F, et al. Limits of normality of quantitative thoracic CT analysis. Crit Care Lond Engl. 2013;17:R93.

23. Vieira SR, Puybasset L, Richecoeur J, Lu Q, Cluzel P, Gusman PB, et al. A lung computed tomographic assessment of positive end-expiratory pressure-induced lung overdistension. Am J Respir Crit Care Med. 1998;158:1571-7.

24. Lu Q, Constantin J-M, Nieszkowska A, Elman M, Vieira S, Rouby J-J. Measurement of alveolar derecruitment in patients with acute lung injury: computerized tomography versus pressure-volume curve. Crit Care. 2006;10:R95.

25. Gattinoni L, Caironi P, Cressoni M, Chiumello D, Ranieri VM, Quintel M, et al. Lung recruitment in patients with the acute respiratory distress syndrome. N Engl J Med. 2006:354:1775-86.

26. Grasselli G, Zangrillo A, Zanella A, Antonelli M, Cabrini L, Castelli A, et al. Baseline characteristics and outcomes of 1591 patients infected with SARS-CoV-2 admitted to icus of the lombardy region, Italy. JAMA 2020;323:1574

27. Pelosi P, D’Andrea L, Vitale G, Pesenti A, Gattinoni L. Vertical gradient of regional lung inflation in adult respiratory distress syndrome. Am J Respir Crit Care Med. 1994;149:8-13.

28. Gattinoni L, Marini JJ, Pesenti A, Quintel M, Mancebo J, Brochard L. The, "baby lung" became an adult. Intensive Care Med. 2016;42:663-73.

29. Gattinoni L, Bombino M, Pelosi P, Lissoni A, Pesenti A, Fumagalli R, et al. Lung structure and function in different stages of severe adult respiratory distress syndrome. JAMA. 1994;271:1772-9.

30. Gattinoni L, Pelosi P, Suter PM, Pedoto A, Vercesi P, Lissoni A. Acute respiratory distress syndrome caused by pulmonary and extrapulmonary disease: different syndromes? Am J Respir Crit Care Med. 1998:158:3-11.

31. Mauri T, Spinelli E, Scotti E, Colussi G, Basile MC, Crotti S, et al. Potential for lung recruitment and ventilation-perfusion mismatch in patients with the acute respiratory distress syndrome from coronavirus disease 2019: Crit Care Med. 2020;1. 
32. Pelosi P, D'Onofrio D, Chiumello D, Paolo S, Chiara G, Capelozzi VL, et al. Pulmonary and extrapulmonary acute respiratory distress syndrome are different. Eur Respir J Suppl. 2003;42:48s-56s.

33. Carsana L, Sonzogni A, Nasr A, Rossi RS, Pellegrinelli A, Zerbi P, et al. Pulmonary post-mortem findings in a series of COVID-19 cases from northern Italy: a two-centre descriptive study. Lancet Infect Dis. 2020. https://doi.org/10.1016/S1473-3099(20)30434-5.

34. Zubieta-Calleja G, Zubieta-DeUrioste N. Pneumolysis and "silent hypoxemia" in COVID-19 Indian. J Clin Biochem. 2020. https://doi.org/10.1007/ s12291-020-00935-0.

35. Grillo F, Barisione E, Ball L, Mastracci L, Fiocca R. Lung fibrosis: an undervalued finding in COVID-19 pathological series. Lancet Infect Dis. 2020. https ://doi.org/10.1016/S1473-3099(20)30582-X.
36. Barisione E, Grillo F, Ball L, Bianchi R, Grosso M, Morbini P, et al. Fibrotic progression and radiologic correlation in matched lung samples from COVID-19 post-mortems. Virchows Arch. 2020. https://doi.org/10.1007/ s00428-020-02934-1.

37. Cox MJ, Loman N, Bogaert D, O'Grady J. Co-infections: potentially lethal and unexplored in COVID-19. Lancet Microbe. 2020;1:e11.

\section{Publisher's Note}

Springer Nature remains neutral with regard to jurisdictional claims in published maps and institutional affiliations.
Ready to submit your research? Choose BMC and benefit from:

- fast, convenient online submission

- thorough peer review by experienced researchers in your field

- rapid publication on acceptance

- support for research data, including large and complex data types

- gold Open Access which fosters wider collaboration and increased citations

- maximum visibility for your research: over $100 \mathrm{M}$ website views per year

At BMC, research is always in progress.

Learn more biomedcentral.com/submissions 